\title{
LETTER
}

\section{Effect of adjunctive tobramycin inhalation versus placebo on early clinical response in the treatment of ventilator-associated pneumonia: the VAPORISE randomized-controlled trial}

\author{
Jason Stokker ${ }^{1}$, Mina Karami $^{2}$, Rogier Hoek ${ }^{1}$, Diederik Gommers ${ }^{3}$ and Menno van der Eerden ${ }^{1^{*}}$ (D)
}

๑ 2020 Springer-Verlag GmbH Germany, part of Springer Nature

\section{Dear Editor,}

The relatively poor response rates seen with intravenous (IV) antibiotic (AB) therapy and the emergence of multidrug-resistant (MDR) microorganisms requires the development of new treatment strategies for ventilatorassociated pneumonia (VAP) [1].

We investigated in a prospective double-blind randomized-controlled trial performed in a single center, whether empiric adjunctive therapy with inhalation tobramycin could ameliorate prognosis in VAP patients (ClinicalTrials.gov Identifier: NCT02440828). Patients with a clinically defined VAP were randomly assigned to a treatment group receiving twice-daily tobramycin inhalation $300 \mathrm{mg}$ and standard IV AB therapy for 8 days or to a control group which received twice-daily placebo inhalation and standard IV AB treatment for 8 days. Inclusion and exclusion criteria are described in the protocol as supplementary file. Primary outcome was treatment failure at day 4, defined as one of the following four criteria present at day 4: (1) no improvement of the $\mathrm{PaO}_{2} / \mathrm{FiO}_{2}$ ratio, (2) persistence of fever $\left(\geq 38{ }^{\circ} \mathrm{C}\right)$ or hypothermia $\left(<35.5^{\circ} \mathrm{C}\right)$ together with purulent respiratory secretions, (3) increase in the pulmonary infiltrates on chest radiograph of $\geq 50 \%$, and (4) occurrence of septic shock or multiple organ dysfunction syndrome, defined as three or more organ system failures not present on day 1 . Secondary outcomes were 30 -day

\footnotetext{
*Correspondence: m.vandereerden@erasmusmc.n

1 Department of Pulmonary Medicine, Erasmus MC, Rotterdam, The Netherlands
}

Full author information is available at the end of the article mortality and number of ventilation free days at day 28 . The target sample size would be 84 patients, which provides an $80 \%$ power to detect a difference of $32 \%$ in cure rate between treatments. The study was approved by independent and local ethics committee (ethical approval number $=$ NL48009.078.14).

The study was terminated prematurely due to insufficient inclusion. Twenty-six patients were included (treatment, $n=13$; control, $n=13$ ) (Table 1). Treatment failure was present in four patients (31\%) of the treatment group and in eight control patients $(62 \%)(p=0.24$, relative risk $=0.5$ ). There was no difference in 30-day mortality (treatment, $n=4(31 \%)$ vs control, $n=4(31 \%)$. The number of ventilation free days at day 28 was 18 days [0-21] in the treatment group and 17 days [5-22] in the control group.

A meta-analysis conducted by $\mathrm{Xu}$ et al. suggests that treatment with aerosolized tobramycin resulted in clinical recovery benefits, but this was mostly based on observational studies [2]. Two recent prospective trials did not show a benefit of inhaled $A B$ therapy as adjunctive treatment for VAP $[3,4]$. The findings of our explorative double-blind randomized-controlled trial failed to show a beneficial effect of adjunctive tobramycin inhalation therapy in the treatment of VAP. However, due to the small number of patients, the current study was underpowered. The relative risk for therapy failure at day 4 in the study group compared to the control group is 0.5 (95\% CI 0.19-1.3), meaning that therapy failure occurred twice as often in the control group. The next step is to investigate whether inhalation antibiotics could be beneficial in certain subgroups, such as an infection with 
Table 1 Baseline values and clinical outcomes

\begin{tabular}{|c|c|c|c|c|c|}
\hline & $\begin{array}{l}\text { Treatment } \\
\text { group, } n=13\end{array}$ & Control group, $n=13$ & $\begin{array}{l}\text { Risk difference ( } 95 \% \\
\text { confidence interval) }\end{array}$ & $\begin{array}{l}\text { Relative risk ( } 95 \% \\
\text { confidence interval) }\end{array}$ & $p$ value \\
\hline \multicolumn{6}{|l|}{ Baseline variables } \\
\hline Age, median [IQR] & $58[42-69]$ & $59[43-66]$ & & & \\
\hline Male, $n(\%)$ & $10(77 \%)$ & $7(54 \%)$ & & & \\
\hline \multicolumn{6}{|l|}{ Smoking } \\
\hline Never & $3(23 \%)$ & $1(8 \%)$ & & & \\
\hline Former & $4(31 \%)$ & $2(15 \%)$ & & & \\
\hline Current & $1(8 \%)$ & $2(15 \%)$ & & & \\
\hline Unknown & $5(39 \%)$ & $8(62 \%)$ & & & \\
\hline Apache II score at inclusion (median) & $21[12-24]$ & $14[13-24]$ & & & \\
\hline CPIS score (median) & $7[5-10]$ & $6[5-9]$ & & & \\
\hline Duration of ventilation before VAP (median) & $7.4[2-22]$ & $15.2[2-63]$ & & & \\
\hline Microbiological confirmation, $n(\%)$ & $10(77 \%)$ & $7(54 \%)$ & & & \\
\hline \multicolumn{6}{|l|}{ Outcome values } \\
\hline Therapy failure, $n(\%)$ & $4(31 \%)$ & $8(62 \%)$ & $31 \%(-6.6$ to $58.3 \%)$ & $0.5(0.19-1.18)$ & 0.24 \\
\hline \multicolumn{6}{|l|}{ Causes of treatment failure ${ }^{a}$} \\
\hline Criteria, no. 1 & $0(0 \%)$ & $2(15 \%)$ & & & \\
\hline Criteria, no. 2 & $1(8 \%)$ & $3(23 \%)$ & & & \\
\hline Criteria, no. 3 & $0(0 \%)$ & $0(0 \%)$ & & & \\
\hline Criteria, no. 4 & $1(8 \%)$ & $0(0 \%)$ & & & \\
\hline 30-day mortality & $4(31 \%)$ & $4(31 \%)$ & $0 \%(-32.4$ to $32.4 \%)$ & $1(0.33-3.06)$ & 1 \\
\hline Ventilation-free days (median) ${ }^{b}$ & $18[0-21]$ & $17[5-22]$ & & & \\
\hline Days in $I C U^{c}$ & $16[7-35]$ & $13[8-17]$ & & & \\
\hline Adverse events, $n(\%)$ & $6(46 \%)$ & $4(31 \%)$ & $-15 \%(-46$ to $19.9 \%)$ & $1.5(0.57-4.13)$ & 0.69 \\
\hline None & $7(54 \%)$ & $9(70 \%)$ & & & \\
\hline Bronchospasm & $1(8 \%)$ & $0(0 \%)$ & & & \\
\hline Renal disfunction & $0(0 \%)$ & $1(8 \%)$ & & & \\
\hline Other & $5(38 \%)$ & $3(23 \%)$ & & & \\
\hline
\end{tabular}

a Criteria for treatment failure: 1. No improvement of the arterial $\mathrm{O}_{2}$ tension to inspired $\mathrm{O}_{2}$ fraction ratio. 2 . Persistence of fever $\left(\geq 38^{\circ}\right)$ of hypothermia $\left(<35.5^{\circ}\right)$ together with purulent respiratory secretions. 3. Increase in the pulmonary infiltrates on chest radiograph of greater than or equal to $50 \%$. 4 . Occurrence of septic shock or multiple organ dysfunction syndrome defined as three or more organ system failures not present on day 1

b Ventilation-free days at day 28 after inclusion

c Days stayed at ICU after inclusion until discharge

MDR microorganisms, as has also been recommended in a recent review [5].

We thank D. van Duijn and P. Ormskerk for study assistance and S. Baart for statistical support.

\section{Electronic supplementary material}

The online version of this article (https://doi.org/10.1007/s00134-019-05914-5) contains supplementary material, which is available to authorized users.

\section{Author details}

${ }^{1}$ Department of Pulmonary Medicine, Erasmus MC, Rotterdam, The Netherlands. ${ }^{2}$ Department of Cardiology, Amsterdam UMC, University of Amsterdam, Amsterdam, The Netherlands. ${ }^{3}$ Department of Intensive Care, Erasmus MC, Rotterdam, The Netherlands.

\section{Funding}

This study was partly funded by Chiesi pharmaceuticals.

\section{Compliance with ethical standards}

\section{Conflicts of interest}

The authors declare that at the time of the study there were no conflict of interest.

\section{Publisher's Note}

Springer Nature remains neutral with regard to jurisdictional claims in published maps and institutional affiliations.

Accepted: 24 December 2019

Published online: 23 January 2020

\section{References}

1. Kalil AC, Metersky ML, Klompas M et al (2016) Management of adults with hospital-acquired and ventilator-associated pneumonia: 2016 clinical practice guidelines by the infectious diseases society of America and the American Thoracic Society. Clin Infect Dis 63(5):e61-e111 
2. Xu F, He LL, Che LQ, Li W, Ying SM, Chen ZH, Shen HH (2018) Aerosolized antibiotics for ventilator-associated pneumonia: a pairwise and Bayesian network meta-analysis. Crit Care 22:301

3. Kollef MH, Ricard JD, Roux D, Francois B, Ischaki E, Rozgonyi Z et al (2016) A randomized trial of the amikacin fosfomycin inhalation system for the adjunctive therapy of Gram-negative ventilator-associated pneumonia: IASIS Trial. Chest 151:1239-1246. https://doi.org/10.1016/j.chest .2016 .11 .026
4. Bayer (BAY41-6551). Inhaled Amikacin Solution BAY41-6551 as Adjunctive Therapy in the Treatment of Gram-Negative Pneumonia (INHALE-1). Clinical Trials.gov. NCT01799993 (2018).

5. Sweeney DA, Kalil AC (2019) Why don't we have more inhaled antibiotics to treat ventilator-associated pneumonia? Clin Microbiol Infect. https:// doi.org/10.1016/j.cmi.2019.04.018 